\title{
Perinatal Mental Health during COVID-19 Pandemic: An Integrative Review and Implications for Clinical Practice
}

\author{
Julia Suwalska ${ }^{1, *}$, , Maria Napierała ${ }^{2}$, Paweł Bogdański ${ }^{1}$, Dorota Łojko $^{2}$, Katarzyna Wszołek ${ }^{3}$, \\ Sara Suchowiak ${ }^{2}$ and Aleksandra Suwalska ${ }^{2}$ (D) \\ 1 Department of Treatment of Obesity, Metabolic Disorders and Clinical Dietetics, Poznan University of \\ Medical Sciences, 60-569 Poznan, Poland; pbogdanski@ump.edu.pl \\ 2 Department of Mental Health, Chair of Psychiatry, Poznan University of Medical Sciences, \\ 60-572 Poznan, Poland; mnapierala@ump.edu.pl (M.N.); lojko@ump.edu.pl (D.Ł.); \\ sara.suchowiak@o2.pl (S.S.); asuwalska@ump.edu.pl (A.S.) \\ 3 Department of Mother and Child Health, Poznan University of Medical Sciences, 60-535 Poznan, Poland; \\ katarzyna.wszolek@ump.edu.pl \\ * Correspondence: jsuwalska@ump.edu.pl
}

check for updates

Citation: Suwalska, J.; Napierała, M.; Bogdański, P.; Łojko, D.; Wszołek, K.; Suchowiak, S.; Suwalska, A. Perinatal Mental Health during COVID-19 Pandemic: An Integrative Review and Implications for Clinical Practice. J. Clin. Med. 2021, 10, 2406. https:// doi.org/10.3390/jcm10112406

Academic Editors: Julie Cwikel and Sarah Kittel-Schneider

Received: 8 April 2021

Accepted: 26 May 2021

Published: 29 May 2021

Publisher's Note: MDPI stays neutral with regard to jurisdictional claims in published maps and institutional affiliations.

Copyright: (c) 2021 by the authors. Licensee MDPI, Basel, Switzerland. This article is an open access article distributed under the terms and conditions of the Creative Commons Attribution (CC BY) license (https:/ / creativecommons.org/licenses/by/ $4.0 /)$.

\begin{abstract}
The COVID-19 pandemic and measures implemented to decelerate its spread have consequences for mental health of societies. The aim of our review was to analyze depressive and anxiety symptoms in perinatal women. The search used PubMed and Web of Science databases. Most studies showed an increase in the prevalence of depression and/or anxiety symptoms. Risk factors identified in our study were mainly related to the possibility of COVID-19 infection, changes in the organization of perinatal care, social isolation and financial problems. Protective factors included social support, the woman's own activity and knowledge about COVID-19. The results of our study point to the importance of the mental health screening including suicide risk assessment in perinatal women. Much of the mental health needs of perinatal women can be met in primary or perinatal care services; however, women with mental health issues should be offered psychiatric consultations and psychological support, and sometimes urgent psychiatric hospitalization is necessary. Healthcare professionals should provide information addressing uncertainty about COVID-19, organization of midwifery and medical care as well as mental health problems and how to get help. Mental health interventions in pregnant women may involve planning physical activity and encouraging to engage in online social activities.
\end{abstract}

Keywords: COVID-19; pandemic; perinatal mental health; depression; anxiety; restrictions; social support; telemedicine; integrative review

\section{Introduction}

On 31 December 2019, China reported a cluster of cases of pneumonia in Wuhan, Hubei Province [1], associated with a novel coronavirus [2]. In February 2020, the World Health Organization (WHO) named the disease caused by it as COVID-19 [3]. Soon, COVID-19 became a threat to global health [4] and spread to almost all countries worldwide and evolved into a pandemic [5]. A year after the original outbreak-on 31 December 2020, the total cumulative count (total cases worldwide) of coronavirus cases including deaths and recovered or discharged patients (cases with an outcome) stood at 83,969,640, and novel coronavirus daily cases worldwide stood at 759,004 [6].

Governments around the world have responded to the coronavirus disease 2019 (COVID-19) pandemic with unprecedented policies aimed to decrease virus transmission by reducing contact among individuals within or between populations. Many policies, such as closing schools and restricting populations to their homes, impose large and visible costs on society [7]. Mental health consequences of COVID-19 pandemic in the general population are associated with quarantine and isolation as well as worrying about one's 
own health, family, friends and acquaintances being infected [8,9]. Public health measures implemented to decelerate the spread of COVID-19, such as physical distancing and travel restrictions, might help to alleviate the burden of healthcare systems, but have unintended consequences for women and families [10]. Such consequences could include gender-based and family violence, as well as a reduction in preventive healthcare-seeking behaviors, such as prenatal care and well-child visits $[9,10]$. Pregnant women and new mothers are a particularly vulnerable group. In this population, an increase in depression prevalence and the exacerbation of other mental health concerns has been observed $[9,10]$. It should be stressed that antenatal and postpartum depression may pose an additional threat to the woman's life since perinatal suicidality is nowadays considered one of the leading causes of maternal mortality in the first 12 months postpartum [11]. Prenatal depression and anxiety also have negative effects on fetal growth and neonatal outcome including a greater incidence of prematurity and low birthweight [12]; symptoms of depression are associated with behavioral or mood disturbances in offspring that can increase their risk of depression in adolescence and adulthood. [13]. Efforts to reduce the prevalence of depression and anxiety should be a public health priority [14].

Researchers from many countries have undertaken studies to determine the impact of the COVID-19 pandemic on depressive and anxiety symptoms in pregnant women and new mothers. A few systematic reviews with meta-analysis following the Preferred Reporting Items for Systematic Reviews and Meta-Analyses (PRISMA) guidelines [15] have been carried out. The results of the reviews concerning antenatal psychological symptoms indicate increased severity of anxiety [16] and increased prevalence of anxiety and depression [17-19] in pregnant women during the COVID-19 pandemic. Based on a systematic review with meta-analysis, Yan et al. [20] found high rates of anxiety, depression and insomnia in pregnant women and new mothers. No comprehensive analysis of factors associated with the worsening of mental state of pregnant and postpartum women during COVID-19 pandemic has been reported.

The aim of the current study was to analyze the prevalence and intensity of mental health problems in pregnant women and new mothers during the COVID-19 pandemic, examine risk factors of depression and anxiety, as well as protective factors, and consider the application of the findings in perinatal care.

\section{Materials and Methods}

Integrative review methods were used as they allow for consideration of studies with varying methodologies and rigor [21].

\subsection{Search Strategy and Study Selection}

We searched the PubMed and Web of Science databases from inception until 4 November 2020. The search terms were: (COVID-19 OR SARS-CoV-2 OR coronavirus) AND (depression OR anxiety OR stress OR mood) AND (pregnancy OR pregnant OR postpartum OR perinatal). The literature search was performed independently and in duplicate by two authors (J.S. and M.N.). The titles and abstracts of the retrieved articles were screened to exclude records that did not meet the inclusion criteria. J.S. and M.N. further reviewed full-text articles. Disagreements between reviewers regarding the study selection were resolved by consensus or by the decision of a third independent reviewer (A.S.). A manual search of references of pertinent articles was performed to identify additional relevant studies.

\subsection{Eligibility Criteria}

Studies were eligible for inclusion if they (1) assessed the mental health status of pregnant women or new mothers during the first wave of the COVID-19 pandemic, (2) used standardized and validated scales for measurement of depressive and anxiety symptoms and (3) were written in English. Only original articles were included. If publications 
presented data from the same study, only the publication with the largest sample size was included.

\subsection{Data Collection Process}

K.W. and S.S. performed the data extraction independently using an Excel spreadsheet. The data were obtained from tables or figures if no direct information was available in the text. Disagreements regarding the data extraction were resolved by consensus or by the decision of A.S.

\subsection{Data Items}

The data items included the following: research type, study title, first author, publication year, country, time of the study, sample size and characteristics of participants, methods of recruitment, screening tools and study outcomes (prevalence of depressive and/or anxiety symptoms, risk and protective factors). No assumptions and simplifications were made.

\subsection{Quality Assessment}

J.S. and K.W. independently evaluated the risk of bias of the included studies using a modified form of the Newcastle-Ottawa scale [22,23]. Disagreements regarding quality assessments were resolved by A.S. Quality assessment criteria were the following: sample representativeness and size, comparability between respondents and non-respondents, ascertainment of depression and anxiety and adequacy of descriptive statistics. The total quality score ranged between 0 and 5 . Studies scoring $\geq 3$ points were regarded as low risk of bias, compared to the studies assessed with $<3$ points that were regarded as high risk of bias [22].

\section{Results}

\subsection{Search Results}

Our initial search identified 292 items. Following removal of 45 duplicates, the titles and abstracts of the remaining 247 records were screened for relevance. Overall, 192 articles were excluded on the following grounds: wrong population (non-perinatal women, pregnant women infected with COVID-19, medical professionals, non-human studies), wrong topic (pharmacotherapy, other viral infections, breastfeeding, somatic diseases in pregnancy, etc.) and non-original articles. In total, 30 articles were included after full-text review. The reasons for the removal of 25 papers were as follows: lack of standardized psychometric tools, disparate populations studied, same populations studied, insufficient quality and non-English language, as well as being a research project, a review and an online posts analysis. Bibliographies of selected articles were screened to identify additional studies, which did not bring additional data. Figure 1 shows the article selection process.

\subsection{General Characteristics of the Studies}

Overall, 30 articles meeting the inclusion criteria were selected for analysis. The general characteristics of the selected studies are presented in Table 1 . Studies were divided into those that assessed both depression and anxiety symptoms and those that assessed only depression or anxiety symptoms. 


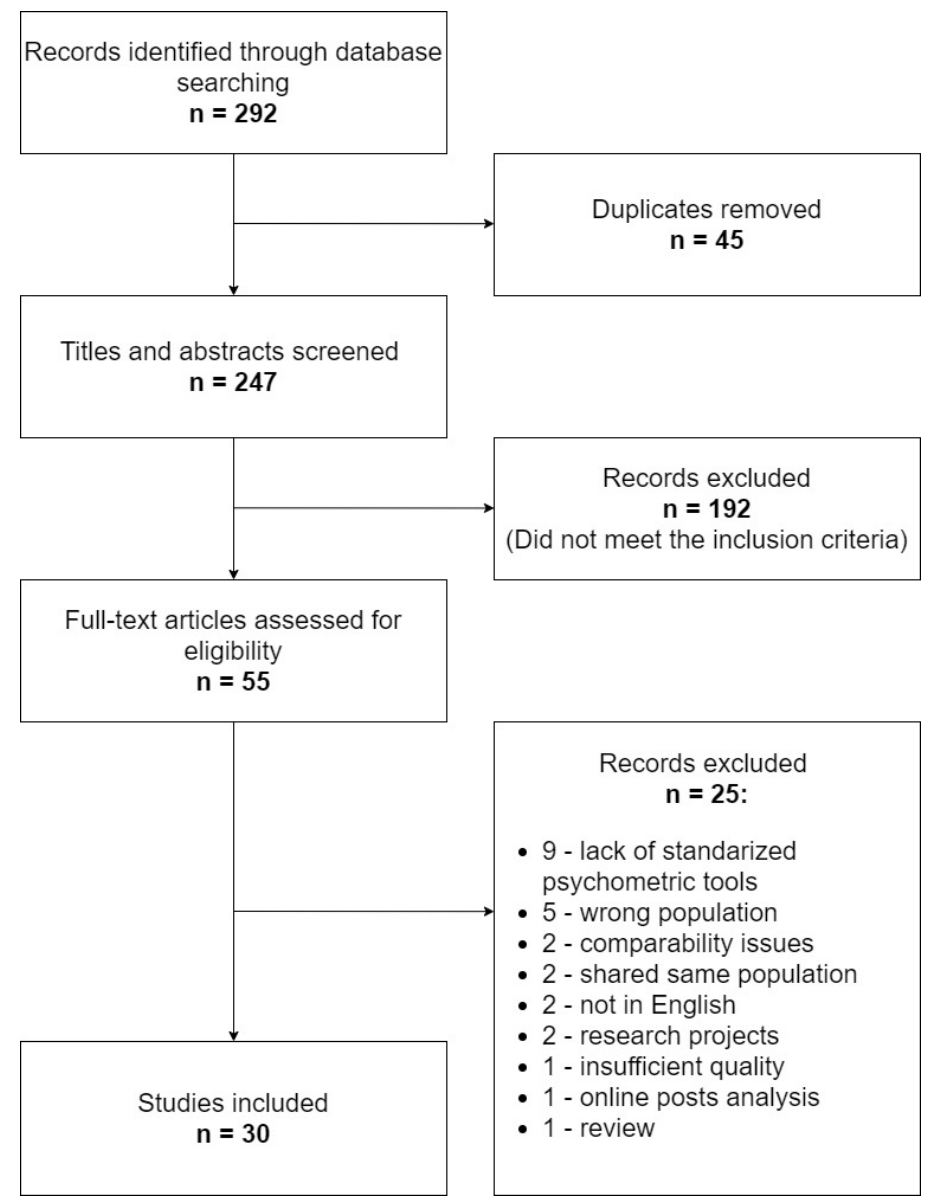

Figure 1. Search flowchart for the selection of articles.

Table 1. Characteristics of the selected studies.

\begin{tabular}{|c|c|c|c|c|c|}
\hline Ref & Country & Time & Participants & Recruitment & Tools \\
\hline \multicolumn{6}{|c|}{ Assessment of depression and anxiety } \\
\hline$[24]$ & Belgium & No information & $\begin{array}{c}\text { 5866:2421 pregnant and } 3445 \\
\text { breastfeeding women }\end{array}$ & Online survey & $\begin{array}{l}\text { EPDS }^{1} \\
\text { GAD-7 }\end{array}$ \\
\hline [25] & Canada & 04.2020 & $\begin{array}{l}1754 \text { pregnant women: } 496 \\
\text { before and } 1258 \text { during the } \\
\text { pandemic }\end{array}$ & $\begin{array}{c}\text { Online survey-social media, } \\
\text { advertisements in prenatal } \\
\text { clinics }\end{array}$ & K10 \\
\hline$[26,27]$ & Canada & 04.2020 & 1987 pregnant women & Online survey—social media & $\begin{array}{l}\text { EPDS }^{1} \\
\text { PROMIS } \\
\text { PRAQ }\end{array}$ \\
\hline [28] & China & 02.2020 & 156 pregnant women & $\begin{array}{l}\text { Online survey-social media } \\
\text { and distributed by doctors }\end{array}$ & $\begin{array}{l}\text { SDS } \\
\text { SAS }\end{array}$ \\
\hline [29] & China & 02-03.2020 & $\begin{array}{c}\text { 859:544 pregnant and } 315 \\
\text { non-pregnant women }\end{array}$ & Online survey—social media & $\begin{array}{l}\text { PHQ-9 } \\
\text { GAD-7 }\end{array}$ \\
\hline$[30]$ & China & $\begin{array}{c}\text { 03-06.2020 } \\
\text { (remission phase) }\end{array}$ & $\begin{array}{l}\text { 625:516 pregnant and } 109 \\
\text { postpartum women }\end{array}$ & $\begin{array}{l}\text { Written survey-hospital } \\
\text { patients }\end{array}$ & $\begin{array}{l}\text { EPDS }^{1} \\
\text { GAD-7 }\end{array}$ \\
\hline [31] & Italy & 03-05.2020 & $\begin{array}{l}\text { 575:389 pregnant and } 186 \\
\text { postpartum women }\end{array}$ & Online survey—social media & $\begin{array}{l}\text { EPDS }^{1} \\
\text { STAI }\end{array}$ \\
\hline [32] & Turkey & No information & 260 pregnant women & $\begin{array}{l}\text { Online survey-hospital } \\
\text { patients }\end{array}$ & $\begin{array}{c}\text { EPDS }^{2} \\
\text { BDI } \\
\text { BAI }\end{array}$ \\
\hline
\end{tabular}


Table 1. Cont.

\begin{tabular}{|c|c|c|c|c|c|}
\hline Ref & Country & Time & Participants & Recruitment & Tools \\
\hline [33] & Turkey & 04-05.2020 & $\begin{array}{l}63 \text { pregnant women before } \\
\text { and during the pandemic }\end{array}$ & $\begin{array}{c}\text { Face-to-face } \\
\text { interviews-hospital patients }\end{array}$ & $\begin{array}{l}\text { IDAS II } \\
\text { BAI }\end{array}$ \\
\hline [34] & Turkey & $06-07.2020$ & 403 pregnant women & Online survey-social media & HADS \\
\hline [35] & USA & $03-04.2020$ & $\begin{array}{l}31 \text { pregnant and postpartum } \\
\text { women }\end{array}$ & $\begin{array}{l}\text { Phone interview and online } \\
\text { survey-social media }\end{array}$ & $\begin{array}{l}\text { PHQ-2 } \\
\text { GAD-7 }\end{array}$ \\
\hline [36] & USA & $04-05.2020$ & 913 pregnant women & $\begin{array}{l}\text { Online survey-medical } \\
\text { records system }\end{array}$ & $\begin{array}{l}\text { PHQ-2 } \\
\text { GAD-7 }\end{array}$ \\
\hline [37] & Qatar & $06-07.2020$ & $\begin{array}{l}288 \text { pregnant and postpartum } \\
\text { women }\end{array}$ & $\begin{array}{l}\text { Written survey-hospital } \\
\text { patients }\end{array}$ & $\begin{array}{l}\text { PHQ-9 } \\
\text { GAD-7 }\end{array}$ \\
\hline \multicolumn{6}{|c|}{ Assessment of depression } \\
\hline [38] & China & $01-02.2020$ & $\begin{array}{l}4124 \text { pregnant women: } 2839 \\
\text { before and } 1285 \text { after the } \\
\text { epidemic declaration in China }\end{array}$ & $\begin{array}{l}\text { Written survey-hospital } \\
\text { patients }\end{array}$ & EPDS $^{3}$ \\
\hline [39] & Hong Kong & $01-04.2020$ & $\begin{array}{c}4531 \text { postpartum women ( } 1 \\
\text { day and } 1 \text { week after } \\
\text { delivery): } 3577 \text { before and } 954 \\
\text { during the pandemic }\end{array}$ & $\begin{array}{l}\text { Written survey-hospital } \\
\text { patients }\end{array}$ & EPDS $^{3}$ \\
\hline [40] & Israel & 03-05.2020 & $\begin{array}{c}369 \text { high-risk pregnant } \\
\text { women: } 279 \text { before and } 90 \\
\text { during the pandemic }\end{array}$ & $\begin{array}{l}\text { Written survey-patients of } \\
\text { high-risk pregnancy units }\end{array}$ & EPDS $^{3}$ \\
\hline [41] & Italy & 03-05.2020 & $\begin{array}{l}192 \text { postpartum women: } 101 \\
\text { before and } 91 \text { during the } \\
\text { pandemic }\end{array}$ & $\begin{array}{l}\text { Written survey-hospital } \\
\text { patients }\end{array}$ & EPDS $^{1}$ \\
\hline [42] & Japan & $05-06.2020$ & 1777 pregnant women & $\begin{array}{c}\text { Online survey-users of } \\
\text { applications }\end{array}$ & EPDS $^{1}$ \\
\hline [43] & Turkey & 06.2020 & $\begin{array}{l}223 \text { postpartum women ( } 48 \mathrm{~h} \\
\text { after delivery) }\end{array}$ & $\begin{array}{l}\text { Written survey-hospital } \\
\text { patients }\end{array}$ & EPDS $^{1}$ \\
\hline [44] & USA & $02-06.2020$ & 485 pregnant women & $\begin{array}{l}\text { Written survey-hospital } \\
\text { patients }\end{array}$ & EPDS $^{4}$ \\
\hline$[45]$ & USA & 04.2020 & 2099 pregnant women & Online survey-social media & EPDS $^{5}$ \\
\hline \multicolumn{6}{|c|}{ Assessment of anxiety } \\
\hline [46] & China & 02.2020 & 1947 pregnant women & $\begin{array}{l}\text { Online survey-social media } \\
\text { and written survey-hospital } \\
\text { patients }\end{array}$ & SAS \\
\hline [47] & China & 02.2020 & 308 pregnant women & $\begin{array}{l}\text { Online survey-hospital } \\
\text { patients }\end{array}$ & SAS \\
\hline [48] & Israel & 03-04.2020 & 403 pregnant women & Online survey—social media & PRAS \\
\hline [49] & Italy & 03.2020 & 178 pregnant women & $\begin{array}{l}\text { Online survey-hospital } \\
\text { patients }\end{array}$ & STAI \\
\hline [50] & Italy & 03-04.2020 & 100 pregnant women & $\begin{array}{l}\text { Written survey-hospital } \\
\text { patients }\end{array}$ & STAI-SF \\
\hline [51] & Turkey & 04.2020 & $\begin{array}{l}203 \text { pregnant and } 101 \\
\text { non-pregnant women }\end{array}$ & $\begin{array}{l}\text { Written survey-hospital } \\
\text { patients }\end{array}$ & STAI \\
\hline [52] & USA & 04.2020 & 788 pregnant women & Online survey—social media & $\begin{array}{l}\text { GAD-7 } \\
\text { PREPS } \\
\text { PRAS }\end{array}$ \\
\hline [53] & USA & 04.2020 & 2740 pregnant women & Online survey—social media & $\begin{array}{l}\text { VAS- } \\
\text { anxiety }\end{array}$ \\
\hline [54] & USA & 04-05.2020 & 4451 pregnant women & Online survey-social media & PREPS \\
\hline
\end{tabular}

Abbreviations: Ref-reference; EPDS—Edinburgh Postnatal Depression Scale, GAD-7—Generalized Anxiety Disorder 7; K10—Kessler Distress Scale; PROMIS-Patient-Reported Outcomes Measurement Information System Anxiety Adult form; PRAQ—Pregnancy-Related Anxiety Questionnaire; SDS—Self-Rating Depression Scale; SAS—Self-Rating Anxiety Scale; PHQ—Patient Health Questionnaire; STAIState-Trait Anxiety Inventory; BDI—Beck Depression Inventory; BAI—Beck Anxiety Inventory; IDAS-II—Inventory of Depression and Anxiety Symptoms II; HADS-The Hospital Anxiety and Depression Scale; PRAS—Pregnancy-Related Anxiety Scale; PREPS-PandemicRelated Pregnancy Stress Scale; VAS—Visual Analogue Scale. EPDS cut-offs: ${ }^{1} \geq 13 ;^{2}>13 ;{ }^{3} \geq 10 ;{ }^{4} \geq 9 / 12 ;^{5} \geq 15$. 
Of the selected papers, in 22 the participants were pregnant women, in 5 they were perinatal women (pregnant, postpartum and breastfeeding) and in 3 they were postpartum women. In total, 13 papers assessed anxiety and depression symptoms, 8 assessed depression symptoms and 9 assessed anxiety symptoms. Studies came from the USA (7), China (6), Turkey (5), Italy (4), Canada (2), Israel (2), Belgium (1), Qatar (1), Japan (1) and Hong Kong (1). The channels of communication were the Internet in most studies, 12 studies used a written survey or a face-to-face interview, while 1 study used telephone communication. The studies differed in their method of recruitment-most online surveys were distributed via social media, while other studies recruited hospital patients. The study by Sade et al. [40] was conducted among hospitalized patients with high-risk pregnancy.

In six studies, the control group consisted of patients studied before the pandemic or the announcement of the epidemic, and in the study by Ayaz et al. [33], the same patients completed questionnaires before and during the pandemic. Zhou et al. and Yassa et al. [29,51] compared pregnant and non-pregnant women.

To assess the severity of depressive symptoms both specific-Edinburgh Postnatal Depression Scale (EPDS), as well as generic-Beck Depression Inventory (BDI) and Patient Health Questionnaire (PHQ), tools were used [55]. The EPDS was the most commonly used tool to assess depressive symptoms. Studies used different cut-offs to assess depressive symptoms-from $\geq 10$ to $\geq 15$, as indicated in Table 1 . Another frequently used tool was the Patient Health Questionnaire (version 2 or 7). The Generalized Anxiety Disorder Scale (GAD-7) and the State-Trait Anxiety Inventory (STAI) were the most commonly used tools to assess anxiety symptoms. Two studies assessed pandemic-related stress experienced by pregnant women using the new instrument, the Pandemic-Related Pregnancy Stress Scale (PREPS). This questionnaire assesses preparedness stress, perinatal infection stress and positive appraisal [56].

\subsection{Depression and Anxiety Symptoms}

The results of studies assessing the prevalence of depressive and anxiety symptoms in perinatal women can be found in Table 2 .

Table 2. Prevalence of depression and anxiety.

\begin{tabular}{|c|c|c|c|}
\hline Reference & Symptoms of Depression & Symptoms of Anxiety & Comparator \\
\hline \multicolumn{4}{|c|}{ Depression and Anxiety } \\
\hline$[24]$ & $\begin{array}{l}\uparrow \text { Pregnancy-25.3\%; } \\
\text { postpartum } 23.6 \%\end{array}$ & $\begin{array}{l}\uparrow 39.4 \% \text { mild; } 13.6 \% \\
\text { moderate-to-severe anxiety }\end{array}$ & $\begin{array}{c}\text { Estimates in Belgium prior to the } \\
\text { pandemic }\end{array}$ \\
\hline [25] & 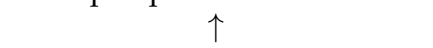 & $\uparrow$ & Pre-pandemic cohort \\
\hline [26] & $\uparrow 37 \%$ & $\uparrow 57 \%$ & Similar pre-pandemic pregnancy cohorts \\
\hline [28] & $\uparrow 50.6 \%$ & $\leftrightarrow 8.3 \%$ & Literature data \\
\hline [29] & $\downarrow 5.3 \%$ & $\downarrow 6.8 \%$ & Non-pregnant women during pandemic \\
\hline [30] & $19.2 \%$ & $31.2 \%$ & None \\
\hline$[31]$ & $\begin{array}{c}\uparrow 34.2 \% \text { (pregnant women) } \\
\uparrow 26.3 \% \text { (postpartum women) }\end{array}$ & $\begin{array}{c}\uparrow 64 \% \text { (pregnant women) } \\
\uparrow 57.7 \% \text { (postpartum women) }\end{array}$ & Literature data \\
\hline [32] & $35.4 \%$ & & None \\
\hline [33] & $\uparrow$ & $\uparrow$ & Test-retest study \\
\hline$[34]$ & $56.3 \%$ & $64.5 \%$ & None \\
\hline [35] & $12 \%$ & $60 \%$ & None \\
\hline$[36]$ & $9.9 \%$ & $11.1 \%$ & None \\
\hline [37] & $\uparrow 39.2 \%$ & $\uparrow 34.4 \%$ & Literature data \\
\hline
\end{tabular}


Table 2. Cont.

\begin{tabular}{|c|c|c|c|}
\hline Reference & Symptoms of Depression & Symptoms of Anxiety & Comparator \\
\hline \multicolumn{4}{|c|}{ Depression } \\
\hline [38] & $\uparrow 29.6 \%$ & & Pre-alert group \\
\hline [39] & $\uparrow 14.4 \%$ & & Pre-alert group \\
\hline$[40]$ & $\leftrightarrow 25.0 \%$ & & $\begin{array}{l}\text { Pre-pandemic hospitalized high-risk } \\
\text { pregnancy group }\end{array}$ \\
\hline [41] & $\uparrow 28.6 \%$ & & Pre-pandemic control group \\
\hline [42] & $17 \%$ & & None \\
\hline [43] & $14.7 \%$ & & None \\
\hline$[44]$ & $\begin{array}{c}\downarrow \text { score } \geq 9 \text { in EPDS- } 15.1 \% \\
\text { score }>128.2 \%\end{array}$ & & Pre-restriction group \\
\hline$[45]$ & $24 \%$ & & None \\
\hline \multicolumn{4}{|c|}{ Anxiety } \\
\hline [46] & & $17.2 \%$ & None \\
\hline [47] & & $\uparrow 14.3 \%$ & General population prior to COVID-19 \\
\hline [49] & & $\uparrow 77.0 \%$ & Literature data \\
\hline [50] & & $68 \%$ & None \\
\hline [51] & & $\uparrow 62.6 \%$ & Literature data \\
\hline [52] & & $\begin{array}{c}\text { Mild-35.6\%; } \\
\text { moderate-21.6\%; severe } \\
\text { anxiety symptoms-21.7\% }\end{array}$ & None \\
\hline
\end{tabular}

Meaning of the symbols: $\uparrow$-higher than the comparator, $\downarrow$-lower than the comparator, $\leftrightarrow$ similar to the comparator.

Most studies have shown an increase in the prevalence of depressive symptoms and/or anxiety. Berthelot et al. [25] showed a significant increase in the prevalence of depressive and anxiety symptoms in a group of pregnant patients before and during the COVID-19 pandemic. Similar results were shown by Ayaz et al. [33], who compared the same group of pregnant patients before and during the pandemic. Results of Wu et al. [38] and Hui et al. [39] pointed to an increase in depressive symptoms in perinatal women following the alert announcement regarding coronavirus infection. Zanardo et al. [41] showed an increase in the number of depressed pregnant women during the pandemic compared to a pre-pandemic group in Italy.

On the other hand, the results of Dong et al. [28] showed that, compared to the literature data prior to pandemic, the anxiety level of pregnant women was the same, while the level of depression was significantly higher. In research of Zhou et al. [29], the prevalence of depression and anxiety was lower among pregnant than non-pregnant women. This is partially consistent with the research of Yassa et al. [51] in which both pregnant and non-pregnant women expressed a higher state of anxiety during the pandemic than the normal population in the literature, but the state of anxiety scores were significantly higher in non-pregnant women. In the study by Sade et al. [40] on women hospitalized at the high-risk pregnancy unit during the COVID-19 strict isolation period, the prevalence of depression was high $(25.0 \%)$, but not higher when compared to women hospitalized before the outbreak of disease.

One study was conducted among pregnant women living in low socioeconomic status environments in New York City [44]. No differences were observed in the mean EPDS values of the women studied in the period before and after the introduction of the restrictions (12 March 2020), but a comparison of the results obtained in the period of 2 February11 March and in the period of 4 May-12 June indicated decreased symptomatology during restrictions.

\subsection{Risk Factors}

Factors which were connected with a higher risk of depression and/or anxiety are listed in Table 3. 
Table 3. Risk factors of depression and/or anxiety symptoms.

\begin{tabular}{|c|c|}
\hline Perinatal care & $\begin{array}{l}\text { Uncertainty and concerns about perinatal care }[26,35] \\
\text { Alterations to prenatal appointments }[53,54,57] \\
\text { Discomfort with hospital and ambulatory visits [34] }\end{array}$ \\
\hline Social factors & $\begin{array}{l}\text { Social isolation [26] } \\
\text { Lack of social support }[31,35,42] \\
\text { Being single }[36,42] \\
\text { Partner's absence at delivery }[31] \\
\text { Tension/conflict at home }[26,53]\end{array}$ \\
\hline Demographic & $\begin{array}{l}\text { Being a woman of color }[36,54] \\
\text { Being an Arab woman }[48] \\
\text { Education level (high-[49], low-[34,53]) } \\
\text { Younger age }[36,42]\end{array}$ \\
\hline Financial & $\begin{array}{l}\text { Low income, financial difficulties }[25,42] \\
\text { COVID-19-related financial stress and income loss }[45,54] \\
\text { Unemployment }[34,42]\end{array}$ \\
\hline $\begin{array}{l}\text { Factors concerning } \\
\text { COVID-19 }\end{array}$ & $\begin{array}{l}\text { Stress of getting infected with COVID-19 [26,35,42,48,52,53] } \\
\text { Suffering subjective symptoms of suspected infection [46] } \\
\text { Perceived risk of having had COVID-19 [54] } \\
\text { Having infected friends/families/colleagues [57] } \\
\text { Self or family member being an essential worker [53] } \\
\text { Living in a location with a large number of COVID-19 cases [46,53] }\end{array}$ \\
\hline Health state & $\begin{array}{l}\text { High-risk pregnancy }[48,52,54] \\
\text { Chronic illness [54] } \\
\text { Previous psychiatric diagnosis }[25,31] \\
\text { Previous adverse experiences during pregnancy [57] }\end{array}$ \\
\hline Insufficient information & $\begin{array}{l}\text { No information about the effects of COVID-19 [34] } \\
\text { Inconsistent messaging from information sources [35] }\end{array}$ \\
\hline
\end{tabular}

Studies have offered various factors connected with increased risk of perinatal depression and anxiety. As it is shown in Table 3, women's worries were related to changes in regular perinatal care and lack of social contacts and support. The lack of presence and support from one's partner during labor and delivery as well as in the first days postpartum has been found to increase symptoms of anxiety and depression in perinatal women [31].

Higher symptoms of depression and anxiety were associated with more concern about threats of COVID-19 to the life of the mother and baby. In the research of Gur et al. [36], women with COVID-19 and pregnancy worries were more likely to meet the screening threshold for anxiety; only pregnancy-specific worries predicted depression screening results.

Living in a location with a large number of COVID-19 cases has been a significant driver of greater changes in pregnancy-related anxiety scores [53]. In the research of Liu et al. [46], pregnant women in Wuhan were about twice as likely to develop anxiety as women in a less-affected Chinese city; however, this was not confirmed by Dong et al. [28].

Some of the studies we analyzed showed significant demographic, cultural and social differences. A higher risk of depression and/or anxiety was found among unemployed and low-income women [25,34,42]. COVID-19-related financial stress has been significantly associated with increased likelihood of a clinically significant depression score, even after adjustment for covariates including participant education and income [45].

The Taubman-Ben-Ari et al.'s study, which compared Jewish and Arab pregnant women, showed that Arab women reported higher levels of COVID-19-related childbirth anxiety and global fear of childbirth [48]. In research of Gur et al. [36], black women were found to be more likely to meet the criteria for depression than white women, but this difference was not significant when accounting for covariates. Women of color reported higher pandemic-related stress in a study by Preis [54]. 


\subsection{Protective Factors}

Factors connected with a reduced risk of depression and/or anxiety symptoms are presented in Table 4.

Table 4. Protective factors.

\begin{tabular}{cl}
\hline & Social support [26,47,48] \\
& Partner emotional support [35] \\
& Low hostility level in close relationships [36] \\
& Use of virtual communication platforms [35] \\
\hline & Information from healthcare workers and televised \\
& pandemic-related information [37] \\
& More knowledge about COVID-19 [46] \\
& Rational perception of COVID-related risk [46,47] \\
\hline \multirow{3}{*}{ COVID-related information } & Physical activity [26,34] \\
& Access to outdoor space [35,54] \\
& Engagement in various healthy behaviors [35,54] \\
\hline \multirow{2}{*}{ Activity } & More self-reliance [36] \\
& Better emotion regulation [36] \\
& Positive attitudes towards online medical consultation [46] \\
\hline \multirow{2}{*}{ Personal } &
\end{tabular}

Many studies have analyzed factors connected with reduced risk of depression and/or anxiety. In qualitive data gathered by Farewell et al. [35], participants identified various sources of resilience, including the use of virtual communication platforms, engaging in selfcare behaviors (e.g., adequate sleep, physical activity and healthy eating), partner emotional support and being outdoors. Lebel et al. [26] found that higher levels of perceived social support and support effectiveness, as well as more physical activity, were associated with lower psychological symptoms. Those with relatively more knowledge about COVID-19 and rational risk perception (not too nervous about epidemic control or going out), were less likely to be anxious [46].

\section{Discussion}

The effects of the COVID-19 pandemic on mental health are still not fully known. Research into this impact in the population and its individual sections is required. It is important to identify which groups are most affected and which methods are most effective in preventing and treating mental disorders in a pandemic [58]. Among the vulnerable groups that need special attention are frontline healthcare workers, children, older people, their caregivers, psychiatric patients and marginalized communities [59]. Pregnant women may also constitute a population vulnerable to mental health disorders during the COVID19 pandemic. Buekens et al. published a call for action for COVID-19 surveillance and research during pregnancy [10]. Additionally, Caparros-Gonzalez et al. [60] postulated the need to assess symptoms of depression and anxiety in pregnant and postpartum women, as well as the risk and protective factors for these symptoms. This literature review responds, so to speak, to these calls [10]. The studies on mental health of pregnant women and new mothers during COVID-19 pandemic were a response to a changing situation, were conducted in different settings, with different groups of respondents and using different tools. The heterogeneity of study designs and inconsistent results clearly indicate the need for summative research - namely reviews, which contribute to delineate the impact of the pandemic on the mental state of pregnant women and new mothers. Previous systematic reviews $[16,17,19,20]$ and a recent rapid review [18] have focused on the prevalence of anxiety and depression among pregnant women and new mothers.

Our review analyzes a greater number of studies than previous systematic literature reviews and provides a multidimensional examination of the prevalence of depressive and anxiety symptoms in perinatal women, including risk and protective factors, which can contribute to the development of recommendations for healthcare professionals. Our 
multidisciplinary research group includes academics and practitioners, doctors from different specialties, psychologists, psychotherapists and practicing midwives. We applied the integrative review method that allows for the combination of diverse methodologies to provide a comprehensive understanding of a particular phenomenon or healthcare problem [21] and has the potential to be directly applied to practice and policy.

\subsection{Anxiety and Depression Symptoms in Pregnant Women and New Mothers}

The studies included in our review showed a great deal of diversity. To minimize this factor as much as possible, we limited the review to papers on the first wave of COVID19-between March and June 2020 [61,62]. We included only papers using validated tools and we focused only on symptoms of anxiety and depression; for clarity reasons, we did not analyze other psychological problems such as insomnia and post-traumatic stress disorder symptoms. The diversity of the papers analyzed also has positive aspects, as it highlights the importance of different risk and protective factors, which can be used in the development of interventions.

The results of our literature review indicate a significant prevalence of depressive and anxiety symptoms in perinatal women during the COVID-19 pandemic. Most of the studies analyzed involved pregnant women [25-29,32-34,36,38,40,42,44-54], five involved a mixed group of pregnant and postpartum women $[24,30,31,35,37]$ and three studies involved new mothers $[39,41,43]$. Significant differences in the prevalence of depressive symptoms (5.3\% to $56.3 \%)$ and anxiety $(6.8 \%$ to $77 \%)$ in the studied population were noted. This is due to the aforementioned heterogeneity of the study groups, the different somatic status of women (high-risk pregnancy vs. normal pregnancy), the situation of the study subjects (at home vs. in hospital), the different economic status of the study subjects (some studies were conducted in a group of women with low socioeconomic status) and ethnicity (women of color, white women, Arab and Jewish women). In most of the studies we observed an increase in depressive and/or anxiety symptoms during the pandemic period $[7,24-26,28,31,33,37-39,47,49]$.

\subsection{Risk and Protective Factors}

The pandemic has significantly changed the lives of expectant and new mothers, reducing their sense of security, limiting social support and causing social isolation. Some of the risk factors identified in our study are closely related to the pandemic, such as fear of infecting oneself, the child and loved ones. Pregnant women are among those who have higher levels of stress related to worries about getting infected or spreading COVID-19 [9]. The women interviewed also pointed to the importance of changes in the organization of perinatal care, online visits and not having a partner at the birth. However, it should be remembered that typical risk factors for mental disorders in the perinatal period also increase in importance during the pandemic (e.g., chronic diseases, low income). Analysis of the studies also made it possible to identify protective factors reducing depression and anxiety symptoms. Social support, especially a partner's emotional support and the woman's own activity during the perinatal period (physical activity, engaging in selfcare behaviors) play a significant role here. Several studies have highlighted the role of knowledge about COVID-19 [26,35,42,48,53] and the importance of information provided by healthcare workers [37].

\subsection{Practical Implications}

In the fight against the COVID-19 pandemic, policymakers and healthcare professionals focus primarily on preventing the spread of the virus and treating those infected. The results of our review made it possible to identify the mental health needs of pregnant women and new mothers and to formulate practical recommendations for action to be taken in primary healthcare and in specialist gynecological-obstetric care. We divided the recommendations into three areas of action: information, screening and intervention. 


\subsubsection{Information for Pregnant Women and New Mothers}

Information for pregnant women and new mothers should address the following issues:

- Uncertainty about COVID-19 and about the impact it may have on pregnancy and perinatal health. This information should come from authoritative sources [46] and be evidence based [34,35];

- Recommendations concerning social isolation behaviors, breastfeeding and impacts of disasters on mental and physical health [35];

- Infection prevention procedures for labor, delivery and postpartum [52];

- The way medical and midwife care is provided in the time of COVID-19 and methods of conducting visits (in the surgery and online) [35];

- Information about mental health and ways to relieve stress among pregnant women and encouraging the use of reliable sources $[25,46]$;

- Information on how to get help and/or psychological support [35].

Information should be provided as early as possible: obtaining it can alleviate some stress and subsequent anxiety [52]. Different ways of providing information should be used, including information technology (websites of the government, ministry of health, healthcare facilities), toll-free helplines answering questions of pregnant women, handouts and information provided by healthcare professionals during visits both in the surgery and online, as well as when arranging appointments. It has been demonstrated that women who had more knowledge about COVID-19 provided by medical professionals showed lower levels of anxiety and depressive symptoms [34]. Attention should therefore be paid to women, particularly by providing information to those who are younger, affiliated to the subsidized regime and with lower levels of education, as this group usually has less knowledge about COVID-19 [63].

\subsubsection{Assessment of Risk Factors and Screening for Depression/Anxiety Symptoms}

- Mental health issues should be addressed during visits—questions should be asked about perceived stress, symptoms of mental health problems and social support [25];

- Screening for psychosocial vulnerabilities and depression/anxiety symptoms should be performed during healthcare visits in all pregnant and postpartum women [35,52];

- It is necessary to pay particular attention to patients from the depression or anxiety risk groups in the times of COVID-19, i.e., single and without social support, younger age, with financial difficulties, unemployed, those with high stress of getting infected, with high-risk pregnancy, with chronic illness, with previous psychiatric diagnosis and with previous adverse experiences during pregnancy;

- It is important to continue to monitor the mood of postpartum patients, especially women with anxiety and depressive disorders in pregnancy [53];

- $\quad$ Remote questionnaires may prove useful in identifying women with mental health problems [49].

\subsubsection{Interventions in Women with Perinatal Mental Health Problems}

In this group of patients, collaboration between perinatal care and mental health services is essential. It is crucial to recognize when consultation/treatment by mental health professionals is necessary. As mentioned above, in perinatal care it should be compulsory for every pregnant woman to be assessed for mental health issues at every stage of her pregnancy and postpartum [64]. Standardized tools can be useful here [55], and questionnaires can also be used remotely [49]. Mental status assessments conducted in perinatal healthcare settings includes suicide risk assessment. In psychiatric settings, suicide risk assessment is one component of an investigation conducted to increase patient safety [65]; asking about suicidal thoughts of a patient who has come to a psychiatrist is considered appropriate. However, healthcare professionals working outside the mental healthcare setting believe that these questions could induce thoughts of self-harm and suicide risk [66], and often avoid asking them. The results of the review by Dazzi et al. [67] suggest that acknowledging and talking about suicide may in fact reduce, rather than 
increase, suicidal ideation, and may lead to improvements in mental health in treatmentseeking populations. Women with mental health issues should be offered psychiatric consultations and psychological support; sometimes urgent psychiatric hospitalization is necessary. The treatment depends on the condition of the patient taking into account the risk of suicide. Some patients require psychological support and counseling $[25,34,46]$, and during the pandemic period, therapy often takes place online.

As mentioned above, telehealth options may be used in screening, treating and monitoring perinatal mental health [53]. The COVID-19 pandemic forced the prenatal care system to reorganize efforts toward more virtual visits [68]. Telehealth in psychiatric care was already developing before the COVID-19 pandemic, and the current situation has confirmed its usefulness in prenatal care [25,53,69-71]. Virtual visits make it possible to provide social distance while reaching people in need quickly, allowing for screening, monitoring and therapy of mental disorders.

Obstetricians, midwives and other health professionals in perinatal care play a crucial role in ensuring health interventions for women nearing or after childbirth. It is more important than ever to carry out activities to promote awareness among perinatal women and identify symptoms of depression and anxiety. Healthcare professionals can be involved in mental health promotions and interventions in pregnant women by planning physical activity for them and encouraging them to engage in social activities [34]. Brief interventions to improve self-efficacy and motivate women to engage in healthy activities could be useful in decreasing anxiety $[40,52]$.

\subsection{Limitations}

Our study has a number of limitations. First, as mentioned previously, the comparability of study results was complicated by a diversity of definitions and measurements of perinatal depression and anxiety. Second, we only included studies conducted during the first wave of COVID-19. Third, a significant proportion of the studies in our review used the Internet for data collection. Although a growing number of researchers are relying on this method, data collected in this way may include better educated, more technology-savvy respondents and exclude perinatal women who do not have access to a computer and the Internet; these minority populations are more impacted by COVID-19 and underrepresented in the studied group [53]. Limitations at the review level have to be stressed. The protocol was not registered prior to the study and only two databases were searched. The eligibility criteria included only articles published in English-language journals. Whereas the screening was performed independently by two reviewers, the level of agreement concerning eligibility was not calculated. A meta-analysis of findings was not performed.

\subsection{Long-Term Effects of the COVID-19 Pandemic}

The COVID-19 pandemic prompted the identification of priorities and long-term research strategies for mental health [72]. Lessons from previous pandemics have helped develop guidelines for international public health strategies [73]. In the context of care for pregnant women and newborn babies, the Center for Disease Control and Prevention developed interim guidelines for obstetric care [74]. However, these recommendations relate to somatic health management. Our findings support the postulate of Thapa et al. [75] and Holmes et al. [72] that appropriate management strategies for the mental health of pregnant women should be developed. Health needs of the population during a pandemic are considered as four 'waves' [76,77] of the pandemic. The first wave involves the immediate mortality and morbidity of COVID-19 pandemic. In many countries most of the efforts of policymakers and healthcare workers are directed towards this first wave. However, it is necessary to simultaneously mitigate the other waves and plan further actions directed at them [77]. The second wave is due to the fact that patients with acute conditions (e.g., myocardial infarction) do not receive care because of lack of access to a specialist or the fact that they do not see a doctor for fear of infection. The third wave is related to the lack 
of routine care for patients with chronic diseases (also due to patients' fear of infection, service reduction). These patients include people with diabetes or mental disorders who are in therapy and require regular visits; as a result of a break in treatment, their condition deteriorates. The fourth wave of healthcare needs is the largest and will last the longest, due to the psychosocial and mental burden of the pandemic. It will likely come to the fore when the spread of the virus is under control. We speculate that the fourth wave will last months or even years after the end of the pandemic. Many of the mental health needs of pregnant and postpartum women are met in primary care or perinatal care services, but some require specialist interventions in mental health settings. Further interventions are needed to prepare for and reduce the severity of the fourth wave [77]. In women at risk of depression counseling, approaches such as interpersonal therapy and cognitive behavioral therapy can be effective [78]. Social support and stress-reduction interventions to promote maternal mental health should be also implemented [79].

It should be stressed that even before the COVID-19 pandemic, perinatal mental health problems were underdiagnosed. Data suggest that only $30 \%-50 \%$ of women with perinatal depression were identified in clinical settings and approximately $15 \%$ of them received treatment [80]. The results of our review indicate that, in most of the studies conducted so far during pandemic, an increase in the prevalence of depression and/or anxiety in perinatal women has been observed. This may only be the beginning, as the social and psychologic effects of the pandemic continue [81]. Our study identifies protective and risk factors and provides recommendations concerning the management of mental health problems in perinatal healthcare settings. It may therefore contribute to the development of strategies for protecting maternal mental health during and after the COVID-19 pandemic.

Author Contributions: Conceptualization, J.S., M.N. and A.S.; methodology, J.S., M.N. and A.S.; investigation, J.S., M.N., K.W., S.S. and A.S.; writing-original draft preparation, J.S., M.N., K.W. and S.S.; writing-review and editing, P.B., D.Ł. and A.S.; visualization, J.S.; supervision, A.S.; project administration, A.S.; funding acquisition, M.N., A.S. All authors have read and agreed to the published version of the manuscript.

Funding: This research was funded by Iceland, Liechtenstein and Norway through the EEA Grants, grant number EOG/19/K4/W/0025U0136.

Institutional Review Board Statement: Not applicable.

Informed Consent Statement: Not applicable.

Data Availability Statement: Not applicable.

Conflicts of Interest: The authors declare no conflict of interest. The funders had no role in the design of the study; in the collection, analyses, or interpretation of data; in the writing of the manuscript, or in the decision to publish the results.

\section{References}

1. WHO. Pneumonia of Unknown Cause-China. Available online: https://www.who.int/csr/don/05-january-2020-pneumoniaof-unkown-cause-china/en/ (accessed on 14 February 2021).

2. WHO. Novel Coronavirus-China. Available online: http://www.who.int/csr/don/12-january-2020-novel-coronavirus-china/ en/ (accessed on 14 February 2021).

3. Anand, K.B.; Karade, S.; Sen, S.; Gupta, R.M. SARS-CoV-2: Camazotz's Curse. Med J. Armed Forces India 2020, 76, $136-141$. [CrossRef]

4. Wang, C.; Horby, P.W.; Hayden, F.G.; Gao, G.F. A novel coronavirus outbreak of global health concern. Lancet 2020, 395, 470-473. [CrossRef]

5. WHO. Announces COVID-19 Outbreak a Pandemic. Available online: https://www.euro.who.int/en/health-topics/healthemergencies/coronavirus-covid-19/news/news/2020/3/who-announces-covid-19-outbreak-a-pandemic (accessed on 14 February 2021).

6. Worldometers. Available online: https://www.worldometers.info/coronavirus/ (accessed on 1 March 2021).

7. Hsiang, S.; Allen, D.; Annan-Phan, S.; Bell, K.; Bolliger, I.; Chong, T.; Druckenmiller, H.; Huang, L.Y.; Hultgren, A.; Krasovich, E. The effect of large-scale anti-contagion policies on the COVID-19 pandemic. Nature 2020, 584, 262-267. [CrossRef] 
8. Vindegaard, N.; Benros, M.E. COVID-19 pandemic and mental health consequences: Systematic review of the current evidence. Brain Behav. Immun. 2020, 89, 531-542. [CrossRef]

9. Brooks, S.K.; Webster, R.K.; Smith, L.E.; Woodland, L.; Wessely, S.; Greenberg, N.; Rubin, G.J. The psychological impact of quarantine and how to reduce it: Rapid review of the evidence. Lancet 2020, 395, 912-920. [CrossRef]

10. Buekens, P.; Alger, J.; Bréart, G.; Cafferata, M.L.; Harville, E.; Tomasso, G. A call for action for COVID-19 surveillance and research during pregnancy. Lancet Glob. Health 2020, 8, 877-878. [CrossRef]

11. Orsolini, L.; Valchera, A.; Vecchiotti, R.; Tomasetti, C.; Iasevoli, F.; Fornaro, M.; De Berardis, D.; Perna, G.; Pompili, M.; Bellantuono, C. Suicide during Perinatal Period: Epidemiology, Risk Factors, and Clinical Correlates. Front. Psychiatry 2016, 7, 138. [CrossRef] [PubMed]

12. Field, T.; Diego, M.; Hernandez-Reif, M.; Figueiredo, B.; Deeds, O.; Ascencio, A.; Schanberg, S.; Kuhn, C. Comorbid depression and anxiety effects on pregnancy and neonatal outcome. Infant Behav. Dev. 2010, 33, 23-29. [CrossRef] [PubMed]

13. Tirumalaraju, V.; Suchting, R.; Evans, J.; Goetzl, L.; Refuerzo, J.; Neumann, A.; Anand, D.; Ravikumar, R.; Green, C.E.; Cowen, P.J.; et al. Risk of Depression in the Adolescent and Adult Offspring of Mothers With Perinatal Depression: A Systematic Review and Meta-analysis. JAMA Netw. Open 2020, 3, e208783. [CrossRef] [PubMed]

14. Borchers, L.R.; Dennis, E.L.; King, L.S.; Humphreys, K.L.; Gotlib, I.H. Prenatal and postnatal depressive symptoms, infant white matter, and toddler behavioral problems. J. Affect. Disord. 2020, 282, 465-471. [CrossRef] [PubMed]

15. Moher, D.; Liberati, A.; Tetzlaff, J.; Altman, D.G. Preferred reporting items for systematic reviews and meta-analyses: The PRISMA statement. BMJ 2009, 339, b2535. [CrossRef]

16. Hessami, K.; Romanelli, C.; Chiurazzi, M.; Cozzolino, M. COVID-19 pandemic and maternal mental health: A systematic review and meta-analysis. J. Matern. Fetal Neonatal Med. 2020, 1-8. [CrossRef]

17. Sun, F.; Zhu, J.; Tao, H.; Ma, Y.; Jin, W. A systematic review involving 11,187 participants evaluating the impact of COVID-19 on anxiety and depression in pregnant women. J. Psychosom. Obstet. Gynecol. 2020, 42, 91-99. [CrossRef] [PubMed]

18. Tomfohr-Madsen, L.M.; Racine, N.; Giesbrecht, G.F.; Lebel, C.; Madigan, S. Depression and anxiety in pregnancy during COVID-19: A rapid review and meta-analysis. Psychiatry Res. 2021, 300, 113912. [CrossRef] [PubMed]

19. Fan, S.; Guan, J.; Cao, L.; Wang, M.; Zhao, H.; Chen, L.; Yan, L. Psychological effects caused by COVID-19 pandemic on pregnant women: A systematic review with meta-analysis. Asian J. Psychiatry 2021, 56, 102533. [CrossRef]

20. Yan, H.; Ding, Y.; Guo, W. Mental Health of Pregnant and Postpartum Women During the Coronavirus Disease 2019 Pandemic: A Systematic Review and Meta-Analysis. Front. Psychol. 2020, 11, 3324. [CrossRef]

21. Whittemore, R.; Knafl, K. The integrative review: Updated methodology. J. Adv. Nurs. 2005, 52, 546-553. [CrossRef]

22. Pappa, S.; Ntella, V.; Giannakas, T.; Giannakoulis, V.G.; Papoutsi, E.; Katsaounou, P. Prevalence of depression, anxiety, and insomnia among healthcare workers during the COVID-19 pandemic: A systematic review and meta-analysis. Brain Behav. Immun. 2020, 88, 901-907. [CrossRef]

23. Wells, G.A.; Shea, B.; Higgins, J.P.; Sterne, J.; Tugwell, P.; Reeves, B.C. Checklists of methodological issues for review authors to consider when including non-randomized studies in systematic reviews. Res. Synth. Methods 2013, 4, 63-77. [CrossRef]

24. Ceulemans, M.; Hompes, T.; Foulon, V. Mental health status of pregnant and breastfeeding women during the COVID-19 pandemic: A call for action. Int. J. Gynaecol. Obstet. 2020, 151, 146-147. [CrossRef] [PubMed]

25. Berthelot, N.; Lemieux, R.; Garon-Bissonnette, J.; Drouin-Maziade, C.; Martel, É.; Maziade, M. Uptrend in distress and psychiatric symptomatology in pregnant women during the coronavirus disease 2019 pandemic. Acta Obstet. Et Gynecol. Scand. 2020, 99, 848-855. [CrossRef]

26. Lebel, C.; MacKinnon, A.; Bagshawe, M.; Tomfohr-Madsen, L.; Giesbrecht, G. Elevated depression and anxiety symptoms among pregnant individuals during the COVID-19 pandemic. J. Affect. Disord. 2020, 277, 5-13. [CrossRef] [PubMed]

27. Lebel, C.; MacKinnon, A.; Bagshawe, M.; Tomfohr-Madsen, L.; Giesbrecht, G. Corrigendum to elevated depression and anxiety symptoms among pregnant individuals during the COVID-19 pandemic journal of affective disorders 277 (2020) 5-13. J. Affect. Disord. 2020, 279, 377-379. [CrossRef] [PubMed]

28. Dong, H.; Hu, R.; Lu, C.; Huang, D.; Cui, D.; Huang, G.; Zhang, M. Investigation on the mental health status of pregnant women in China during the Pandemic of COVID-19. Arch. Gynecol. Obstet. 2020, 303, 463-469. [CrossRef] [PubMed]

29. Zhou, Y.; Shi, H.; Liu, Z.; Peng, S.; Wang, R.; Qi, L.; Li, Z.; Yang, J.; Ren, Y.; Song, X.; et al. The prevalence of psychiatric symptoms of pregnant and non-pregnant women during the COVID-19 epidemic. Transl. Psychiatry 2020, 10, 1-7. [CrossRef]

30. Zeng, L.N.; Chen, L.G.; Yang, C.M.; Zeng, L.P.; Zhang, L.Y.; Peng, T.M. Mental health care for pregnant women in the COVID-19 outbreak is urgently needed. Women Birth 2020, 34, 210-211. [CrossRef]

31. Molgora, S.; Accordini, M. Motherhood in the Time of Coronavirus: The Impact of the Pandemic Emergency on Expectant and Postpartum Women's Psychological Well-Being. Front. Psychol. 2020, 11, 567155. [CrossRef]

32. Durankuş, F.; Aksu, E. Effects of the COVID-19 pandemic on anxiety and depressive symptoms in pregnant women: A preliminary study. J. Matern. Fetal Neonatal Med. 2020, 1-7. [CrossRef]

33. Ayaz, R.; Hocaoğlu, M.; Günay, T.; Yardımcı, O.D.; Turgut, A.; Karateke, A. Anxiety and depression symptoms in the same pregnant women before and during the COVID-19 pandemic. J. Perinat. Med. 2020, 48, 965-970. [CrossRef]

34. Kahyaoglu Sut, H.; Kucukkaya, B. Anxiety, depression, and related factors in pregnant women during the COVID-19 pandemic in Turkey: A web-based cross-sectional study. Perspect. Psychiatr. Care 2020. [CrossRef] 
35. Farewell, C.V.; Jewell, J.; Walls, J.; Leiferman, J.A. A Mixed-Methods Pilot Study of Perinatal Risk and Resilience During COVID-19. J. Prim. Care Community Health 2020, 11. [CrossRef]

36. Gur, R.E.; White, L.K.; Waller, R.; Barzilay, R.; Moore, T.M.; Kornfield, S.; Njoroge, W.F.M.; Duncan, A.F.; Chaiyachati, B.H.; Parish-Morris, J.; et al. The Disproportionate Burden of the COVID-19 Pandemic Among Pregnant Black Women. Psychiatry Res. 2020, 293, 113475. [CrossRef]

37. Farrell, T.; Reagu, S.; Mohan, S.; Elmidany, R.; Qaddoura, F.; Ahmed, E.; Corbett, G.; Lindow, S.; Abuyaqoub, S.; Alabdulla, M. The Impact of the COVID-19 Pandemic on the Perinatal Mental Health of Women. J. Perinat. Med. 2020, 48, 971-976. [CrossRef]

38. Wu, Y.; Zhang, C.; Liu, H.; Duan, C.; Li, C.; Fan, J.; Li, H.; Chen, L.; Xu, H.; Li, X.; et al. Perinatal depressive and anxiety symptoms of pregnant women during the coronavirus disease 2019 outbreak in China. Am. J. Obstet. Gynecol. 2020, 223, 240.e1-240.e9. [CrossRef] [PubMed]

39. Hui, P.W.; Ma, G.; Seto, M.T.Y.; Cheung, K.W. Effect of COVID-19 on delivery plans and postnatal depression scores of pregnant women. Hong Kong Med. J. 2020, 26, 113-117. [CrossRef] [PubMed]

40. Sade, S.; Sheiner, E.; Wainstock, T.; Hermon, N.; Yaniv Salem, S.; Kosef, T.; Lanxner Battat, T.; Oron, S.; Pariente, G. Risk for Depressive Symptoms among Hospitalized Women in High-Risk Pregnancy Units during the COVID-19 Pandemic. J. Clin. Med. 2020, 9, 2449. [CrossRef]

41. Zanardo, V.; Manghina, V.; Giliberti, L.; Vettore, M.; Severino, L.; Straface, G. Psychological impact of COVID-19 quarantine measures in northeastern Italy on mothers in the immediate postpartum period. Int. J. Gynaecol. Obstet. 2020, 150, 184-188. [CrossRef]

42. Matsushima, M.; Horiguchi, H. The COVID-19 Pandemic and Mental Well-Being of Pregnant Women in Japan: Need for Economic and Social Policy Interventions. Disaster Med. Public Health Prep. 2020, 1-6. [CrossRef]

43. Oskovi-Kaplan, Z.A.; Buyuk, G.N.; Ozgu-Erdinc, A.S.; Keskin, H.L.; Ozbas, A.; Moraloglu Tekin, O. The Effect of COVID-19 Pandemic and Social Restrictions on Depression Rates and Maternal Attachment in Immediate Postpartum Women: A Preliminary Study. Psychiatr. Q. 2020, 92, 675-682. [CrossRef]

44. Silverman, M.E.; Medeiros, C.; Burgos, L. Early pregnancy mood before and during COVID-19 community restrictions among women of low socioeconomic status in New York City: A preliminary study. Arch. Women's Ment. Health 2020, 23, 779-782. [CrossRef] [PubMed]

45. Thayer, Z.M.; Gildner, T.E. COVID-19-related financial stress associated with higher likelihood of depression among pregnant women living in the United States. Am. J. Hum. Biol. 2020, 33, e23508. [CrossRef]

46. Liu, X.; Chen, M.; Wang, Y.; Sun, L.; Zhang, J.; Shi, Y.; Wang, J.; Zhang, H.; Sun, G.; Baker, P.N.; et al. Prenatal anxiety and obstetric decisions among pregnant women in Wuhan and Chongqing during the COVID-19 outbreak: A cross-sectional study. Bjog Int. J. Obstet. Gynaecol. 2020, 127, 1229-1240. [CrossRef]

47. Yue, C.; Liu, C.; Wang, J.; Zhang, M.; Wu, H.; Li, C.; Yang, X. Association between social support and anxiety among pregnant women in the third trimester during the coronavirus disease 2019 (COVID-19) epidemic in Qingdao, China: The mediating effect of risk perception. Int. J. Soc. Psychiatry 2020. [CrossRef]

48. Taubman-Ben-Ari, O.; Chasson, M.; Abu-Sharkia, S. Childbirth anxieties in the shadow of COVID-19: Self-compassion and social support among Jewish and Arab pregnant women in Israel. Health Soc. Care Community 2020. [CrossRef]

49. Mappa, I.; Distefano, F.A.; Rizzo, G. Effects of coronavirus 19 pandemic on maternal anxiety during pregnancy: A prospectic observational study. J. Perinat. Med. 2020, 48, 545-550. [CrossRef] [PubMed]

50. Saccone, G.; Florio, A.; Aiello, F.; Venturella, R.; De Angelis, M.C.; Locci, M.; Bifulco, G.; Zullo, F.; Di Spiezio Sardo, A. Psychological impact of coronavirus disease 2019 in pregnant women. Am. J. Obstet. Gynecol. 2020, 223, 293-295. [CrossRef] [PubMed]

51. Yassa, M.; Yassa, A.; Yirmibeş, C.; Birol, P.; Ünlü, U.G.; Tekin, A.B.; Sandal, K.; Mutlu, M.A.; Çavuşoğlu, G.; Tug, N. Anxiety levels and obsessive compulsion symptoms of pregnant women during the COVID-19 pandemic. Turk. J. Obstet. Gynecol. 2020, 17, 155-160. [CrossRef] [PubMed]

52. Preis, H.; Mahaffey, B.; Heiselman, C.; Lobel, M. Pandemic-related pregnancy stress and anxiety among women pregnant during the coronavirus disease 2019 pandemic. Am. J. Obstet. Gynecol. MFM 2020, 2, 100155. [CrossRef]

53. Moyer, C.A.; Compton, S.D.; Kaselitz, E.; Muzik, M. Pregnancy-related anxiety during COVID-19: A nationwide survey of 2740 pregnant women. Arch. Women's Ment. Health 2020, 23, 757-765. [CrossRef]

54. Preis, H.; Mahaffey, B.; Heiselman, C.; Lobel, M. Vulnerability and resilience to pandemic-related stress among U.S. women pregnant at the start of the COVID-19 pandemic. Soc. Sci. Med. 2020, 266, 113348. [CrossRef]

55. Suchowiak, S.; Wszołek, K.; Suwalska, J.; Łojko, D.; Suwalska, A. Screening for perinatal depression: A review of tools and barriers. Neuropsychiatr. I Neuropsychol. 2020, 15, 60-69. [CrossRef]

56. Preis, H.; Mahaffey, B.; Lobel, M. Psychometric properties of the Pandemic-Related Pregnancy Stress Scale (PREPS). J. Psychosom. Obstet. Gynaecol. 2020, 41, 191-197. [CrossRef]

57. Zeng, X.; Li, W.; Sun, H.; Luo, X.; Garg, S.; Liu, T.; Zhang, J.; Zhang, Y. Mental Health Outcomes in Perinatal Women During the Remission Phase of COVID-19 in China. Front. Psychiatry 2020, 11, 571876. [CrossRef]

58. Hotopf, M.; Bullmore, E.; O'Connor, R.C.; Holmes, E.A. The scope of mental health research during the COVID-19 pandemic and its aftermath. Br. J. Psychiatry 2020, 217, 540-542. [CrossRef] [PubMed] 
59. Dubey, S.; Biswas, P.; Ghosh, R.; Chatterjee, S.; Dubey, M.J.; Chatterjee, S.; Lahiri, D.; Lavie, C.J. Psychosocial impact of COVID-19. Diabetes Metab. Syndr. 2020, 14, 779-788. [CrossRef] [PubMed]

60. Caparros-Gonzalez, R.A.; Ganho-Ávila, A.; Torre-Luque, A. The COVID-19 Pandemic Can Impact Perinatal Mental Health and the Health of the Offspring. Behav. Sci. 2020, 10, 162. [CrossRef]

61. Iftimie, S.; López-Azcona, A.F.; Vallverdú, I.; Hernàndez-Flix, S.; de Febrer, G.; Parra, S.; Hernández-Aguilera, A.; Riu, F.; Joven, J.; Camps, J.; et al. First and second waves of coronavirus disease-19: A comparative study in hospitalized patients in Reus, Spain. medRxiv 2020. [CrossRef]

62. Salzberger, B.; Buder, F.; Lampl, B.; Ehrenstein, B.; Hitzenbichler, F.; Holzmann, T.; Schmidt, B.; Hanses, F. Epidemiology of SARS-CoV-2. Infection 2020, 49, 233-239. [CrossRef]

63. Parra-Saavedra, M.; Villa-Villa, I.; Pérez-Olivo, J.; Guzman-Polania, L.; Galvis-Centurion, P.; Cumplido-Romero, Á.; SantacruzVargas, D.; Rivera-Moreno, E.; Molina-Giraldo, S.; Guillen-Burgos, H.; et al. Attitudes and collateral psychological effects of COVID-19 in pregnant women in Colombia. Int. J. Gynaecol. Obstet 2020, 151, 203-208. [CrossRef]

64. RCOG. Coronavirus Infection and Pregnancy; Royal College of Obstetrics and Gynaecologists: London, UK, 2020.

65. Wu, C.Y.; Chang, C.K.; Hayes, R.D.; Broadbent, M.; Hotopf, M.; Stewart, R. Clinical risk assessment rating and all-cause mortality in secondary mental healthcare: The South London and Maudsley NHS Foundation Trust Biomedical Research Centre (SLAM BRC) Case Register. Psychol. Med. 2012, 42, 1581-1590. [CrossRef] [PubMed]

66. Bajaj, P.; Borreani, E.; Ghosh, P.; Methuen, C.; Patel, M.; Joseph, M. Screening for suicidal thoughts in primary care: The views of patients and general practitioners. Ment. Health Fam. Med. 2008, 5, 229-235.

67. Dazzi, T.; Gribble, R.; Wessely, S.; Fear, N. Does asking about suicide and related behaviours induce suicide ideation? What is the evidence? Psychol. Med. 2014, 44, 3361-3363. [CrossRef]

68. Peahl, A.F.; Smith, R.D.; Moniz, M.H. Prenatal care redesign: Creating flexible maternity care models through virtual care. Am. J. Obstet. Gynecol. 2020, 223, 389.e1-389.e10. [CrossRef]

69. Madden, N.; Emeruwa, U.N.; Friedman, A.M.; Aubey, J.J.; Aziz, A.; Baptiste, C.D.; Coletta, J.M.; D'Alton, M.E.; Fuchs, K.M.; Goffman, D.; et al. Telehealth Uptake into Prenatal Care and Provider Attitudes during the COVID-19 Pandemic in New York City: A Quantitative and Qualitative Analysis. Am. J. Perinatol. 2020, 37, 1005-1014. [CrossRef] [PubMed]

70. Holcomb, D.; Faucher, M.A.; Bouzid, J.; Quint-Bouzid, M.; Nelson, D.B.; Duryea, E. Patient Perspectives on Audio-Only Virtual Prenatal Visits Amidst the Severe Acute Respiratory Syndrome Coronavirus 2 (SARS-CoV-2) Pandemic. Obstet. Gynecol. 2020, 136, 317-322. [CrossRef] [PubMed]

71. Hermann, A.; Deligiannidis, K.M.; Bergink, V.; Monk, C.; Fitelson, E.M.; Robakis, T.K.; Birndorf, C. Response to SARS-Covid19-related visitor restrictions on labor and delivery wards in New York City. Arch. Women's Ment. Health 2020, 23, 793-794. [CrossRef] [PubMed]

72. Holmes, E.A.; O'Connor, R.C.; Perry, V.H.; Tracey, I.; Wessely, S.; Arseneault, L.; Ballard, C.; Christensen, H.; Cohen Silver, R.; Everall, I.; et al. Multidisciplinary research priorities for the COVID-19 pandemic: A call for action for mental health science. Lancet. Psychiatry 2020, 7, 547-560. [CrossRef]

73. WHO. Resolutions And Decisions. In Proceedings of the World Health Organization Fifty-Eighth World Health Assembly, Geneva, Switzerland, 16-25 May 2005.

74. CDC. Centers for Disease Control and Prevention (CDC). Interim Considerations for Infection Prevention and Control of Coronavirus Disease 2019 (COVID-19) in Inpatient Obstetric Healthcare Settings; Updated 20 May 2020. Available online: https: //www.cdc.gov / coronavirus/2019-ncov/hcp/inpatient-obstetric-healthcare-guidance.html (accessed on 23 February 2021).

75. Thapa, S.B.; Mainali, A.; Schwank, S.E.; Acharya, G. Maternal mental health in the time of the COVID-19 pandemic. Acta Obstet. Et Gynecol. Scand. 2020, 99, 817-818. [CrossRef]

76. Jenkins, E.K.; McAuliffe, C.; Hirani, S.; Richardson, C.; Thomson, K.C.; McGuinness, L.; Morris, J.; Kousoulis, A.; Gadermann, A. A portrait of the early and differential mental health impacts of the COVID-19 pandemic in Canada: Findings from the first wave of a nationally representative cross-sectional survey. Prev. Med. 2021, 145, 106333. [CrossRef]

77. O'Connor, K.; Wrigley, M.; Jennings, R.; Hill, M.; Niazi, A. Mental health impacts of COVID-19 in Ireland and the need for a secondary care mental health service response. Ir. J. Psychol. Med. 2020, 1-9. [CrossRef]

78. O'Connor, E.; Senger, C.A.; Henninger, M.L.; Coppola, E.; Gaynes, B.N. Interventions to Prevent Perinatal Depression: Evidence Report and Systematic Review for the US Preventive Services Task Force. JAMA 2019, 321, 588-601. [CrossRef]

79. Accortt, E.E.; Wong, M.S. It Is Time for Routine Screening for Perinatal Mood and Anxiety Disorders in Obstetrics and Gynecology Settings. Obstet. Gynecol. Surv. 2017, 72, 553-568. [CrossRef] [PubMed]

80. Cox, E.Q.; Sowa, N.A.; Meltzer-Brody, S.E.; Gaynes, B.N. The Perinatal Depression Treatment Cascade: Baby Steps Toward Improving Outcomes. J. Clin. Psychiatry 2016, 77, 1189-1200. [CrossRef] [PubMed]

81. Osborne, L.M.; Kimmel, M.C.; Surkan, P.J. The Crisis of Perinatal Mental Health in the Age of Covid-19. Matern. Child Health J. 2021, 25, 349-352. [CrossRef] [PubMed] 